\title{
The Socio-economic Value of Sports: Strengthening Social Capital through Football
}

\author{
Djen Djalal ${ }^{1}$ \\ ${ }^{1}$ Facultas Ilmu Keolahragaan (FIK), Universitas Negeri Makassar (UNM), Indonesia \\ Correspondence: Djen Djalal, Facultas Ilmu Keolahragaan (FIK), Universitas Negeri Makassar (UNM), Jalan. \\ A.P.Pettarani Makassar 90222, Indonesia. Tel: 62-411-869-834. E-mail: djenlal15@gmail.com
}

Received: February 19, 2015 Accepted: May 7, 2015 Online Published: June 14, 2015

doi:10.5539/jsd.v8n6p16 URL: http://dx.doi.org/10.5539/jsd.v8n6p16

\begin{abstract}
This study aims to: examine the aspect of social capital in sports; examine the contribution of sport in strengthening social capital; examine the use of sport as a place for individual development and also to examine the process of internalization and socialization of social capital on the individual players. It is a descriptive study. The qualitative method is used since the paper describes the social interaction patterns in football. In collecting the data, the researcher has acted as the major research tool. The data collected include: (1) symptoms of social interaction in sports which consist of social contact, communication, and forms of social interaction, (2) the indication of social capital in football, and (3) implications of football to the individual development of the players. The data consists of both the primary and secondary data. Regarding the techniques used in collecting the data, this study uses the review of documents, interviews, and observations. The data obtained, has been analyzed qualitatively. The results show that sport contributes to the strengthening of social capital. It strengthens cooperation and working together, improves social networks, personal qualities as individuals and society. The functions of the football promote features of social capital.
\end{abstract}

Keywords: socio-economic, sports values, sports, social capital, and football

\section{Introduction}

\subsection{Introduce the Problem}

Nowadays, society condition reflects unfavorable situation which impact on the social unity, cohesion, solidarity, and order of things. The present patterns in people's behavior within society, demonstrate social dysfunction. It tends to be disintegrated and weakens the social network. This can be seen from anarchic behavior, conflicts, unhealthy competition, unproductive attitudes, subjectiveness, and unpatterned social networks.

However, in regard to the above, there are two main points which became the basis of this study on football viewed from a social capital perspective. These points were: (1) the society condition which reflects a social capital deficiency, and (2) the understanding of football as a social phenomenon and its explanation from the sociological perspective.

Various factors have prompted the weakening of social capital. One of them is the present situation which has led to the formation of negative socio-cultural patterns. Hasbullah (2006), Firth (1966) and Parkinson (1967) have expressed that studies conducted in the mid and the late 1960's established similar results regarding the Malay (or Indonesian) culture. They found that people of Malay (Indonesian) culture or background were uninventive or uninnovative. Besides, the people of this culture are quickly satisfied with the achievement of simple needs; are wasteful, and love depending on others. They tend to envy with one's success and have weak work ethics. This is in line with Ni'am (2008) who asserts that destructive social phenomenon (e.g polarization, fragmentation, systemic stratification, and disintegration) can arise violent and anti-integrative behavior which eventually create social alienation and egocentrism.

Social relations do not have definite space between tradition, trust, high empathy, and openness to the new value. Social situation developed in each local culture tends to hinder the adaptation of new values which is positive.

Relating to the network, cooperation network cannot solve the society problem, such as poverty, underdevelopment, inequality, and unemployment. As a result, there is apathies behavior. It even causes dominated behavior from those who dominate economics and politics aspect to marginal society. Regarding this, 
Lickona (1992) and Hasbullah (2006) state that some destructive phenomenon cause unstable social condition. Another factor stays on the policy in managing human resources and human capital that ignore social capital aspect. The management, in this case, does not focus on the benefit of cooperation network, constructive relationship, and mutual trust relation among the society components. In bureaucracy, social capital even is not used as a basis in making the policy of development program. Furthermore, the quality of bureaucracy is not used as social capital which is connected to the network that should work effectively.

The deficiency of social capital presented in society requires strengthening and development. The study conducted by Rivai (2007) found that in doing their job, Bugis society, especially the fisherman community namely AnetuE- Kaca Sopeng, implemented social capital which was appropriate with their social and cultural life. Meanwhile, Nopembri's (2008) study attempts to inform the relation of sport and social capital. He found futsal as one of the sports which could develop social skill. He also found that futsal created associative behavior which is based on the norms determined in a social network.

Several studies have shown that sport can give a contribution in strengthening and developing social capital. This is in accordance with the idea of Hall (1999) that measurements of social capital are premised on the extent to which individuals have regular contacts with others, beyond the sphere of the family or the market, and notably the kinds of face to face relations of relative equality associated with participation in common endeavors. Social capital is gained from the contracts with sports clubs, and can be maintained in a network.

Football can be viewed as a symptom of micro-social environment. In other words, sports is considered to have a similar system with a social system. Football, for example, has a hierarchical structure. It has referee to justify the match. Each player has different task. They do their job professionally. They are also attached to the norms and values. If all of these work well, it can show positive impact on the common life.

Strengthening social capital is required, especially in term of: (1) creating social cohesion. This is because society members have to work in a strong network or cooperating system. (2) Creating social cohesion. This is because in society, members have to be disciplined and have strong commitment to the values, norms, and rules. (3) Creating socio-psychological stability- such that the society members do not act emotionally. (4) Prompting the society members to be innovative. (5) Managing the duty and authority based on the principles of equality, justice, and solidarity. According to Ni'am (2008), football has great potential in forming social capital. Football playing techniques reflect the bond of reciprocity feeling. In addition, football has strong and wide social network management.

Studies related to the strengthening of social capital through football are still limited. Most of the studies focus on the relation of social capital to sport in general, social capital and poverty, social capital in certain communities (i.e. community and marginalized urban community), or social capital in economics perspective. Social capital in football can be constructed based society values. Football can be used as an educational tool for the society to maintain and strength social relationships. With sports, even though each member of the community may have different tasks; they still have strong social cohesion when it comes to sports. Football is said to be having a great potential for the strengthening of social capital. In other words, it cannot create social capital to community members.

Based on the above fact, this study is aimed to investigate the strengthening of social capital through football. The object of this study is Makassar Football Association, known as PSM. PSM is chosen for two reasons. First, the characteristic of playing games by PSM (i.e is motivated, straightforward, and courageous). This kind of playing (which is characterized with unique features) should be examined in order to discover whether or not it gives positive or negative influence in strengthening social capital. Another factor is that PSM has fanatic spectators. This kind of behavior can be of positive or negative effect to games. In a negative perspective, it can lead to violence, riots, and aggression. In a positive positive perspective, it can contribute to positive solidarity which does not disturb social order. This study cannot be separated from socio-cultural factors have contributed to the development of professional football.

\subsection{Social Network Theory}

In social studies, social network theory does not use atomistic and normative approaches (Burt, 1987). Atomistic approach focuses on the actor's decision making it isolated from other actors. Meanwhile, normative approach focuses on culture and socialization, in which, in an isolated condition, the actor experiences internalization process of norms and values. These two focuses are not appropriate with the focus of this study which looks at the objective bonds that correlate the society members individually and collectively (Ritzer and Goodman, 2003). Therefore, social structure approach is used in this study. This approach attempts to understand the bond patterns which correlate the society members. Besides, this approach is able to trace the social structure phenomenon on 
the basis part of emerged network pattern and form complex social system. Actors, in this approach, are not free to act since they stay on the structure social that press them (Wellman, 1983)

According to Wellman (1983) as cited by Ritzer and Goodman (2003) there are three principles in social network theory. Those principles are: (1) the bond between the actors is symmetrical and reciprocal. (2) The bond of each individual should be analyzed in the context of wider network structure. (3) The structured social bond forms various types of systemic network. It also possibly forms transitive network.

\subsection{Social Action Theory}

Weber defines social action as individual action that has subjective meaning and is directed to others (Sunarto, 1993). For Weber, social reality is something based on social motivations and actions (Johnson, 1986). Therefore, sociological study attempts to understand and interpret social action as well as interaction. In subjective meaning, a social action requires empathy, the ability to put ourselves in other's condition when we are taking a part in social interaction process.

According to Simmel (Routledge, London, 1990) the process of social interaction is indicated by several actions and reactions (stimuli and response). In these actions and reactions, there are signs that should be understood. Blumer (1971) as cited by Sunarto (1993) formulates the main idea of symbolic interactionism. He states that human action is full of meaningful symbols and has different characteristic. Besides, human action also occurs in social interaction (Blumer, 1971; Sunarto, 1993).

The basis of human action is psychological process. This psychological process include: (1) impulse or motivation that rises the stimulus and response; (2) perception, in which human interpret the stimulus and respond to it in line with their perception; (3) manipulation, the phase of considering and studying the object before doing an action; and (4) consumption, doing an action to fulfill the impulse need (Ritzer and Goodman, 2003).

In a social interaction point of view, social capital deals with four things which are elaborated below: Self-concept. A human being is a self-conscious organism which means that human beings are able to see themselves as their mind object and interact with themselves. This concept describes human potential which can be developed into a social capital, such as self-concepts regarding the expectation of social ideals and the expectation of themselves in accordance with society's expectation. If we develop this concept, however, it can be used as a basis to develop social skills; Interaction concept- in interacting with other people, human beings will place themselves into other people's position. If this works well, social function will have emerged; Collective action- it is defined as an activity that can accommodate and assimilate the difference into the same vision; and Action is psychological process- this indicates that social interaction is an act of self- and subjective consciousness.

\subsection{Social Interaction in Football}

Football is a place for the players to do social interaction. The interaction occurred is based on the self-awareness and other people's awareness. As an external factor, this social interaction can control and affect the action pattern. Mutual interest becomes its purpose and motivation (Max Weber as noted by Veegar, 1986).

In the perspective of symbolic interactionism, social interaction process in football is viewed as a place to develop the players' personality. The member of the group will experience the development process in the club. Mead (1934) a theorist of symbolic interactionism, points out that the development of an individual's personality depends on one's membership to a group.

Social interaction in football constructs a response to a stimulus. According to Sumanto (1993) a stimulus does not necessarily construct a response. It should pass the phase of consideration, assessment and interpretation of situation. In this process, the individual can give meaning to a stimulus received.

Social interaction is a process through social contact and communication. Narwako and Suyanto (2004) affirm that sociologically, there are two requirements for social interaction. Social contact is the first process of social interaction which occurs due to the action and response. In communicating with others, then, individual will give a meaning and interpretation toward the action, in which all of them are determined by different social context. In communicating, the individual also will use symbols, such as gestures or words, which are standard and connoted similar meaning. The communication is verbal communication. Nevertheless, it can be also in the form of non-verbal communication (Sunarto, 1993), in which one interprets others' behavior. Social interaction is performed through communication media.

Social contact can be positive or negative. In positive way, it leads to cooperation. On the other hand, in negative 
way, it leads to conflict. It even does not form social interaction. In addition, social contact can be occurred in three forms. It can occur between individuals, between individual and groups or vice versa, and between a group and the other groups.

Social interaction is a reciprocal social relation between individual. It also involves mind and emotion. According to Mead (1934) and Sunarto (1993) social interaction creates mind and self-concept which is used to create communication symbols through self-concept and society. In social interaction, individual is actively participated in forming the society. Society then influences individual as well as forms his identity.

Social interaction has both integrative potency and social cohesion, such as assimilation, compromise, accommodation, and integration. Social interaction also has dissociative potency, such as competition and conflict. Social interaction in football has two characteristic, which are associative and dissociative. In other words, besides having integration norm and social cohesion, it has a tendency to create a conflict, high aggression, and disobedience to the football norms.

\subsection{Social Capital in Football}

Football basically can be used as a place to shape people's behavior. However, social life, nowadays, reflects symptoms of social disorder. It can be seen from anarchic behavior that occurs everywhere, horizontal conflict, and deviant behavior. To handle this situation, sport, especially football, is required to set rules that govern it. Football, in this case, has two integrated values, which are intrinsic and extrinsic. Intrinsic values are those values which are found within football. Meanwhile, extrinsic values are those values formed as a result of the construction of external factors which are assimilated with the intrinsic values. Culture, as human behavior, can be understood as collective problem solving solution (Cohen, 1955)

In cultural point of view, football is an activity which is based on the existing norms and values. Football traditionally takes part on society's cultural aspect. All football communities are even loyal to their favorite team (Natakusumah, 2008).

Football as a social activity, it is in line with social capital as one of the components of a social system. Putnam (1993) states that social capital is a social system that facilitate coordination and cooperation for mutual benefit stuck in networks and society. Meanwhile, Natakusumah (2008) affirms that football is a teamwork, institution, and organization. The solid combination between individual and team work is the key of success in playing football.

Football has some positive impacts. It can help to build social characteristics and social obligations. Besides, football can strengthen social capital through its social cohesion, wide network, tolerance, inclusiveness, and community defense. Besides, it also encourages to the optimal performance. Unfortunately, people often ignore social traits. They prefer to be individualistic and emotional. Thus, this can cause the social crack.

\section{Method}

This study was descriptive qualitative. Qualitative method was used since this study qualitatively describe social interaction pattern in football in relation to strengthening social capital. In collecting the data, the researchers acted as a research tool. The researcher also placed personal object of the study as the unit of analysis. The data collected were: (1) symptoms of social interaction in a sport that consisted social contacts, communication, and forms of social interaction, (2) the indication of social capital in football, and (3) implications of football to the development of the players' personality. The above data were gained through primary and secondary data sources. Regarding the techniques used in collecting the data, this study used documentation, interview, and observation. The data gained, then, were analyzed using qualitative analysis approach.

\subsection{Determining the Source of Data}

This study was phenomenologist. It collected the data from the information given by three groups of informants. These informants were: (1) Key informants- informants that gave important information needed for this study, such as football manager, referees, football sponsors, observers, and society leaders. (2) Main informantsinformants that are directly engaged in social situation and interaction in football, such as players, coach, and officers. (3) Additional Informant- informants that gave important information although they are not directly engaged in social situation, such as spectators and participants. The information on the number informants involved in this study is given in Table 1 below: 
Table 1. Informants as the data sources

\begin{tabular}{cllc}
\hline No. & Types of informants & \multicolumn{1}{c}{ Informants elements } & Total \\
\hline 1. & Key Informants & Football manager, Referees, and Observers & 8 \\
2. & Main Informants & Players, Coach, and Officers & 10 \\
3. & Additional Informants & Spectators and Participants & 6 \\
& & Total & 24 \\
\hline
\end{tabular}

The above informants were used as the respondents to gain the data needed. From the above informants, it was expected that this study would get the complete data which were in line with its purpose. Purposive sampling was used in determining the informants as the premier data source (Hamid, 1998).

\subsection{Data Collection Techniques}

Data collection was required for data analysis. There were two data collection techniques used in this study, which were observation and in-depth interview. These two data collection techniques were used to collect qualitative data which would be interpreted and described in the data analysis.

\subsection{Data Analysis}

There were four steps in analyzing the data. They were transcription, organizing, recognizing, and coding. Regarding the techniques used in analyzing the data, this study used data selection, presentation, and conclusion (Miles and Huberman, 1984). Selection phase is the process of selecting raw data gained from the field note or information recorded on the field. Presentation phase is a process of arranging the data that has been selected into a series of information. In qualitative study, according to Sugiyono (2005), data presentation was presented in the form of brief description, chart, the relation between categories, and flowchart.

The process of analyzing the data was done continuously during and after collecting the data. By doing this, it was assumed that the validation of the data in this study has been achieved. Besides, the data also could be used to answer the formulated research questions. Therefore, data ambiguity could be avoided.

\section{Results}

\subsection{Testing the Validity of the Findings}

This test was used to see the consistency of the finding gained from various data sources. Sugiyono (2005) notes that validity and reliability test in qualitative study includes internal validity test, external validity test, reliability test, and data objectivity test.

\subsection{Analysis and Interpretation}

The Phenomena of Social Micro in Football

\subsubsection{Social Interaction Aspect}

In football, the process of interaction uses symbols. The symbols have a meaning and value for the participants on the clubs. The symbols can be material or physical form, such as the symbols of the club pride, custom, or nickname (e.g PSM, Rosters from East; PERSIJA, Kemayoran Tiger; PERSIB Bandung, Bandung Tiger, Manchaster United, Red Devil; andAC Milan, The Dream Team). In a game, symbolic gesture is expressed by the players, such as raising their hand (means that give the ball). Besides, it is also used by a coach in giving the instruction to the player, such as hand gesture or facial expression.

Another social interaction occurred in the field is that the players do some actions because they understand the meaning of their action. For instance, a player shakes the opponent player's hand because he does a foul. The other example is that, the number written on the players' custom describes his position and role in the team. In addition, football players have the ability to understand their opponent movement, and respond to it. From this explanation, it can be seen that football has various symbols that can be understood by the players and used as a basis to do some actions.

On the field, the players' movement is full of symbolic gesture. This becomes one of the strategies to win the game. Players' movement can be easily interpreted by their friends or their opponent. One example is the signal of right and effective ball position. A sign language, in football, is very important to unify the movement when there is no opportunity to communicate. The Description of Social Interaction in Football: 


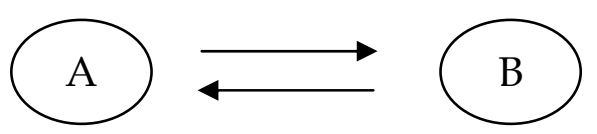

Figure 1. The Interaction between the players ( A to B, vice versa)

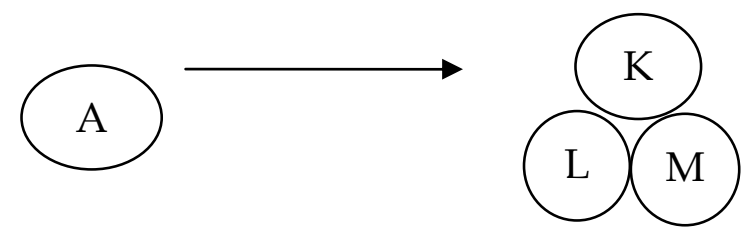

Figure 2. The interaction between a player and his team

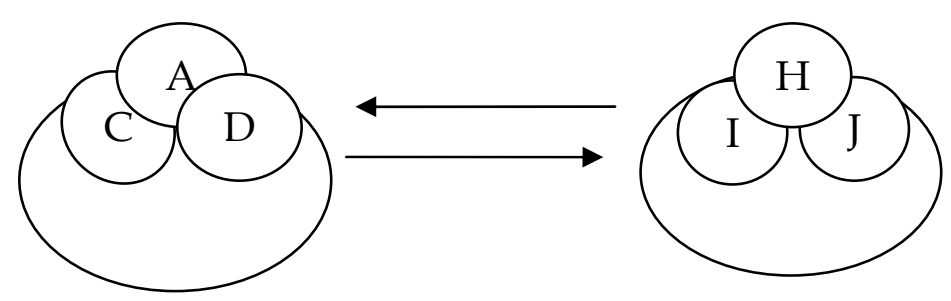

Figure 3. Interaction between teams

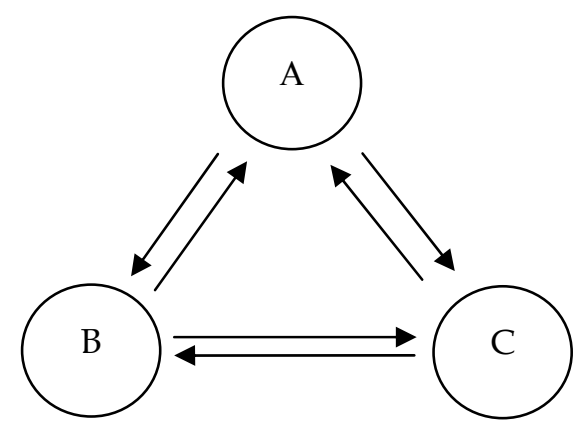

Figure 4. The Interaction of three directions (team, the other team, and referee)

Social interaction performed by the players creates reciprocal influence. The influence occurred is the result of the interaction between each individual, individual and group, as well as a group and the other group. This influence will give an effect on the players' mind, feeling, experience, behavior, norms, and perspective. According to network theory, this is showed symmetric and reciprocal influence and wide network structure (Wellman, 1993). The influence transferred to the player, in this case, has individual characteristic. Besides, it demonstrates the participation on the match network structure or club network structure.

In a football match, the players perform both rational and irrational action. They sometimes obey and disobey the rule of the match. In sociology, irrational action performed by the players can be categorized into two types, which are subjective and deviate action. Irrational action is usually caused by psychological pressure experienced by the players. For instance, this is occurred when the spectators disturb ongoing match or when the referee does not objective in regulating the course of the match. Tense situation also can trigger players' psychological pressure.

Stimulus and response experienced by the football players can be classified into three elements. They are physical, social, and economical element. Physical element deals with the expectation to get achievement and prestige. Social element is related to the responsibility as a member of a team. Meanwhile, economical element concerns with income, welfare and socio-economical status in society. 


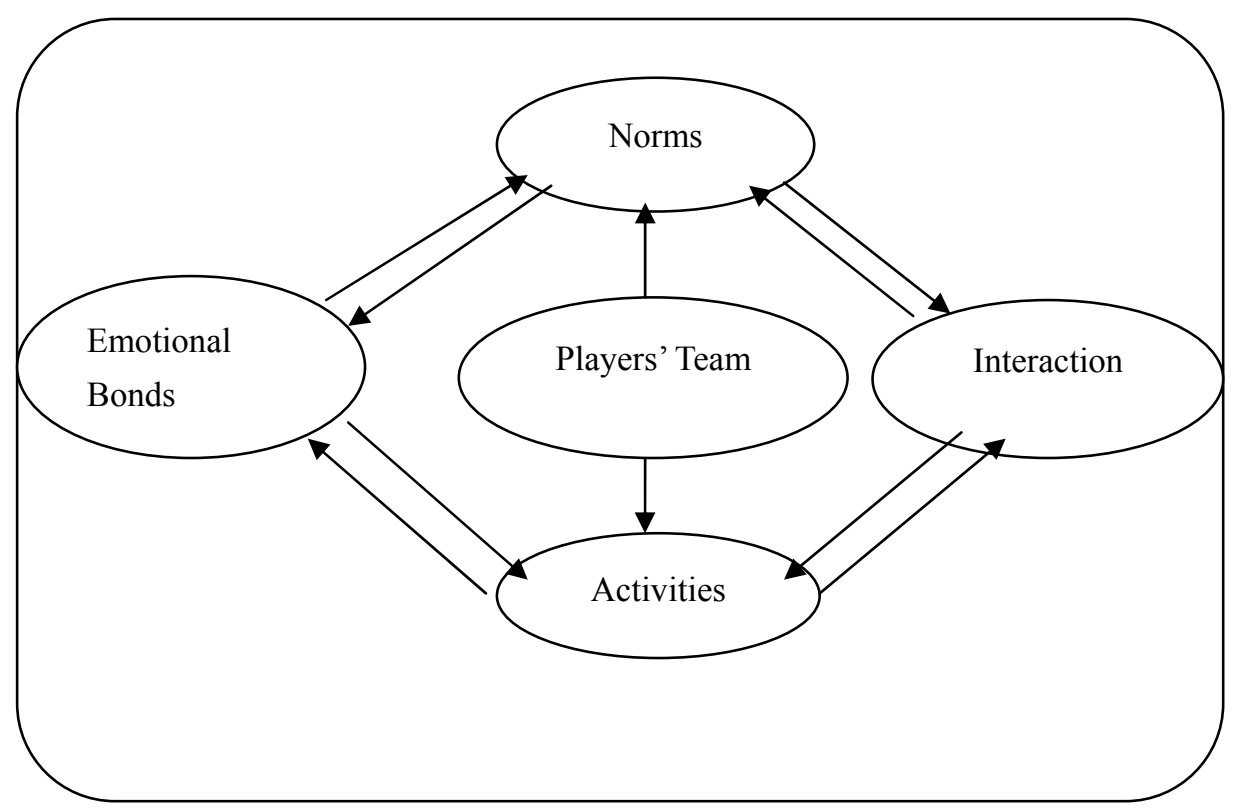

Figure 5. Team's internal interaction system

In a football match, the opponent's action will be responded with a high sense of competition. Each player, in this case, has competitiveness. They are also prompted to maintain the integrity of their team. This is because football is an activity that requires both collective and individual skill. These two skills should be combined to face a competitive match.

As previously mentioned, in football match, there is reciprocal influence. This influence has five characteristics that will be explained below:

- The relation of internal reciprocal influence. This relation is based on the emotional bonds that have been built in community which has collective objectives.

- The relation of external reciprocal influence. This relation is built based on the competitive motives. Thus, each team prepares both individual and collective skills.

- The relation of both internal and external reciprocal influence. This relation is managed in the playing norms which are represented in the form of collective behavior pattern on the field.

- Referee and his assistant have responsibility to control collective behavior on the field. Referee will apply the playing norms that give both positive and negative influences to the match situation played by the players.

- The players' awareness can control the collective behavior patterns occurred on the field. Individual's awareness, in this case, is required to regulate the interaction on the match.

The function of reciprocal influence received by the football players is to achieve the equilibrium. Sociologically, equilibrium is a social ability in creating social stability. Therefore, football players stay on the referee's control, in which referee is a main component that can maintain the playing equilibrium and stability. Fortunately, every player has automatic feeling to refuse everything that threatens the playing stability.

There is normative reference that is used as a consensus between two football teams. The purpose of this reference is to stabilize the match. If the football players obey this normative reference, the match will run well. Nevertheless, the players sometime create tense situation or conflict. This will trigger reaction from the opponent, and give negative influence.

Cooperation and communication is also occurred in a football match. The meaning of cooperation in this case is to manage the playing pattern by obeying match consensus. Even though two teams competes each other, they are stuck to the agreement of preventing the conflict. According to Veeger (1986), this cooperation is known as antagonistic cooperation. In this cooperation, each individual has to adapt to the cooperation that have been agreed. Antagonistic cooperation has become a part of social situation in a football match. This can be seen from the football players' effort to maintain the match equilibrium. Regarding this, conflict theory states that social 
tense, emotion, and conflict has a function as a safety when large-scale conflict occurs. In other words, conflict symptoms can create social cohesion and order:

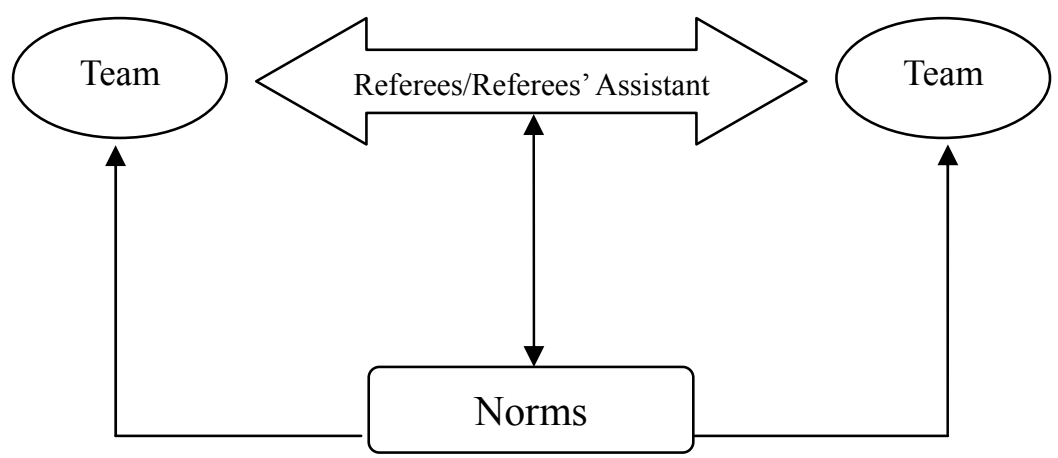

Figure 6. Antagonistic cooperation between teams

Football players' stability is influenced by psychological pressure created by spectators, referee, leadership, and playing objectivity. These external stimuli will be responded by interpreting the situation. For instance, a football player catches the signal given by the coach. He can understand the meaning of the given signal, in which he should strengthen the defense or do an aggression. He then responds the given signal by changing the way he played. The signal given by the coach, in this case, is a stimulus that can influence players' action.

From the above explanation, it can be concluded that football fulfills the requirement and the principle of social interaction in term of network relation and adaptation. The relation leads to the formation of community. The relation also has both associative and dissociative characteristics. George Simmel as cited by Veegar (1986) mention five principles required in the process of social interaction. Those principles are: (1) society consists of network relation between individual causing them to be united and actions causing them to be adapted. (2) The relation occurred has different characteristic, and lead to the formation of community. (3) Social unities are formed not only from integrated and harmonious reaction, but also from dissociative situation. (4) Social unity has different time intensity. There is a group who has high and low interaction frequency.

Football has four functions which are associated with social aspect. They are social emotion, socialization, social integration, and mobilization. The clear description of social function of football can be seen in the following Table.

Table 2. Social function of football

\begin{tabular}{|c|c|c|c|c|c|c|}
\hline \multirow{2}{*}{ No. } & \multirow{2}{*}{ Social Function of Football } & \multirow{2}{*}{ Indicators } & \multicolumn{4}{|c|}{ Answer Scale } \\
\hline & & & 4 & 3 & 2 & $\mathbf{1}$ \\
\hline \multirow{2}{*}{1.} & \multirow{2}{*}{ Social Emotion } & 1. Controlling the emotin & 25 & 9 & 3 & \\
\hline & & 2. Easily changing & 32 & 2 & 8 & 8 \\
\hline \multirow{5}{*}{2.} & \multirow{5}{*}{ Socialization } & 1. Adapting & 43 & 3 & 3 & 1 \\
\hline & & 2. Learning from experience & 35 & 5 & 7 & 3 \\
\hline & & 3. Influencing each other & 35 & 10 & 5 & - \\
\hline & & 4. Communicating & 40 & 5 & - & 5 \\
\hline & & 5. Using symbol & 36 & 6 & 2 & 8 \\
\hline \multirow{4}{*}{3.} & \multirow{4}{*}{ Integration } & 1. Cooperation & 47 & - & - & 3 \\
\hline & & 2. Preventing conflict & 41 & & 6 & 3 \\
\hline & & 3. Playing fair & 39 & 8 & 3 & 4 \\
\hline & & 4. Obeying the agreements & 36 & 10 & 3 & 3 \\
\hline \multirow{3}{*}{4.} & \multirow{3}{*}{ Mobilization } & 1. Working hard to gain achievement & 43 & - & 7 & - \\
\hline & & 2. Dynamics & 39 & 10 & 1 & - \\
\hline & & 3. Mobility as a team & 39 & 5 & 5 & - \\
\hline
\end{tabular}


As previously mentioned, football is an activity that gives the impact to the players' socio-psychological aspect. This is usually represented in the form of irrational action, in which the players respond an action emotionally. This action can be triggered by various factors, such as unsporting behaviors showed by the opponent, mistakes done by a teamwork, unfair match, etc. Fortunately, all of these emotional symptoms are not expressed by the players since they want to prevent the conflict.

Football game is a place to socialize. The players, in this case, attempt to adapt new condition, object and behavior. On this process, there is a role taking, in which they try to settle in other people position. In taking this role, the players can act either objectively or subjectively. They also attempt to identify the other people behavior. From all of this process, socialization can indirectly develop self-concept, concept dealt with players' expectation (i.e. ideals, achievement, and prestige.). This is in line with Mead (1934) who states that human is an organism aware of self. In other words, human are objectively aware to their reality. They also realize the importance of subjective factor in socialization.

Football is a team playing, in which it demonstrates cooperation and cohesiveness to achieve collective goals. This shows that football has social integration function. This function is able to unite the difference of players' social, cultural background. The differences occurred, in this case, is organized in line with the characteristic of football management. Therefore, cooperation and cohesiveness is the only thing that is seen. Football also has mobility function. As it has been known, every players are competed each other to get an achievement and prestige. This will give an impact on their social status movement, from the lower level to the higher level of social status.

\subsubsection{Social Capital Aspect in Football}

Besides as a place to build individual and social network, football has potency to build capital social. Football is physical activity that very popular in society. From football, trust can be developed.

\subsubsection{Trust}

Trust is one of social capital elements. Honesty and openness is basis to build a trust. Regarding football, the football players attempt to maintain the trust given by their coach, fellow players, managers, and spectators. Football communities also usually ask their team to maintain the given trust.

The measurement of social capital in football is based on the players' trust in a team. This trust is represented on their action, in which they play the game according to their position in a team. Besides, trust also can be reflected in the form of admitting a mistake and receiving the other's team win. Even though the football players sometimes behave emotionally, in general, most of them show positive response in accepting defeat from other teams. The following table shows the value of trust mentioned before.

Table 3. Trust value in football

\begin{tabular}{clcccc}
\hline & & \multicolumn{5}{c}{ Answer Scale } \\
\cline { 3 - 6 } No. & \multicolumn{1}{c}{ Trust Elements } & 4 & 3 & 2 & 1 \\
\hline 1. & Playing according to position & 39 & 5 & 6 & \\
2. & Fair Play & 31 & 13 & 6 & \\
3. & Ability to control ourselves & 40 & 3 & 7 & \\
4. & Admitting the mistake done & 45 & 3 & 2 & \\
5. & Discipline on the role & 37 & 7 & 3 & 3 \\
\hline & & $\mathbf{N}=\mathbf{5 0}$ & & & \\
\hline
\end{tabular}

\subsubsection{Reciprocity}

Football playing techniques shows players' reciprocal attitude. Football game also demonstrates a lot of give-and-take between the players in a team. It even gives mutual benefits between the players. For example, a striker cannot create a goal since he stays in disadvantages position. To handle this, he gives the ball to his friend which has wide opportunity to create a goal.

In football game, players' selfishness sometimes occurs. Fortunately, it does not dominate the game. The most visible thing in football is the understanding of each other position. A player who has high individual skill 
understands the position of his teammate. He does not underestimate his teammate who has low individual skill. The detail explanation of reciprocity values occurred in football presents on the Table 4 below.

Table 4. Reciprocity values in football

\begin{tabular}{llllll}
\hline \multirow{2}{*}{ No. } & \multirow{2}{*}{ Reciprocity Element } & \multicolumn{3}{c}{ Answer Scale } \\
\cline { 3 - 6 } & & 4 & 3 & 2 & 1 \\
\hline 1. & Understanding the teammate skill & 28 & 8 & 7 & 7 \\
2. & Knowing the teammate position & 41 & 8 & 1 & - \\
3. & Directional movement & 31 & 9 & 7 & 3 \\
4. & Supporting each others & 32 & 10 & 8 & - \\
5. & Noticing signal given by the teammate & 29 & 10 & 8 & 3 \\
\hline $\mathbf{N}=\mathbf{5 0}$ & & & & \\
\hline
\end{tabular}

\subsubsection{Participation}

The mobility of football team is determined by the participation of each player. The players, in this case, attempt to get involve on the match according to the game pattern determined by the coach. Game pattern, here, is defined as a regulation that determines the position of the players on a match.

Task is one of the factors influencing and determining the players' participation, considering each player has a role according to their task in a team. Players' participation is usually represented in the form of individual skill movement. Besides, players' participation usually refers to the team unity. Although football players have individual role in controlling the ball, their role should be a collective work that is controlled and coordinated well. The coordination and control functions between each player stay on the player captain. Regarding the implementation, sign language or gesture is usually used in communicating. The football players usually can understand and interpret the signals well.

Players' participation also stays on the players' awareness in performing their individual and collective responsibility. This responsibility is in accordance with their position in a team. Players' responsibility can be seen in the cohesiveness in performing playing pattern which is determined by the coach.

Players' participation is structured participation. It means that the pattern has been arranged as a strategy to achieve the collective purpose. Participation is usually followed by objective awareness (of individual awareness) to play the role. It is also followed by subjective awareness. Subjective awareness is represented in the form of external factors which prompt the improvement of the playing quality. For instance, when the opponent has high competitiveness, we should increase our competitiveness in order to be balanced.

Furthermore, participation shows solidarity in each team member. From relation aspect, solidarity in football has organic pattern. The priority of this kind of pattern is relation which is based on the distribution of position and function in presented structure. As noted by George Simmel 'communities with good social relations, tend to have functional and rational working patterns. The participation element in football is described in the following table.

Table 5. Participation elements in football

\begin{tabular}{llllll}
\hline \multirow{2}{*}{ No. } & Participation Elements & \multicolumn{3}{c}{ Answer Scale } \\
\cline { 3 - 6 } & & 4 & 3 & 2 & 1 \\
\hline 1. & Participation in keeping the cohesiveness of the team & 26 & 9 & 7 & 8 \\
2. & Participation in performing instructions given by the coach & 31 & 8 & 11 & - \\
3. & Participation in playing according to the playing pattern & 40 & - & 7 & 3 \\
4. & Participation in obeying the decision made by referee & 30 & 12 & 8 & - \\
5. & Participation in respecting the opponent & 29 & 10 & 8 & 3 \\
\hline
\end{tabular}


Players' participation can strengthen team's solidarity (team internal solidarity). Besides, each player in a team has a responsibility to the match. Therefore, although they are competed, they still have to responsible and participate in maintaining the relation with the opponent.

\subsubsection{Social Network}

In network theory, network concept refers to the bond and network patterns which correlate society members, either in the level of social structure or social situation (Ritzer and Goodman, 2005). In accordance with the above statement, Wellman (1983) affirms that network patterns built in society form complex social systems. Both theories indicate social phenomenon in the aspect of macro structure, which consist of values, norms, and organization structure, and the relation in micro level, such as private relation, motives, and member's action based on perspective.

Accurately, network system in football consists of two patterns. First, it has individual pattern, in which it involves individual player with another network component. Second, it has social network in the form of wide scale network, in which it involves various social components and certain groups (i.e. business, art, transportation, security, etc),

A football player, especially who has high mobility in form of transfer, is usually moved to the other club. This player definitely has a wide and strong network. This kind of network make a football player familiarize with the other players' characteristic, culture, and traditions.

From social network, it shows that football is managed by the various components which have a role in structural, formal, and informal sectors. When there is a football match, especially in Mattoangin Stadium, one of the sectors the most benefitted is informal sector, such as merchants and workers. This means that football can open the network in low society strata. Football also can move informal economic sector around Mattoangin stadium. In addition, football also can build a network in high society strata and various social structures in society.

Football playing technique describes a strong network. The network consists of players, managers, coach, sponsor, football community, and society. Football network, as previously mentioned, can be seen from player transfer. Player transfer shows that football develops inter-cultural and inter-national network. For example, The Football Association of Indonesia (PSSI) allows every clubs which are joint Indonesia Super League (LSI) to use foreign players. This means that the network of Indonesia football, especially PSM Makassar, has opened the inter-territorial and inter-cultural network. The network built, in this case, is a part of the process of social capital development.

Furthermore, football has a good cooperation technique. Players' contribution becomes a basis to build cooperation, either inside or outside the match. Cooperation in strengthening network is influenced by player physical factors and external factors, such as football norms. Physical factors can be emotional bond as a team which is competed with the other team. It can be also expectation to play as a squad of the team.

The power of football depends on the network that is built by several components and community. Component in football consist of sponsor and merchant in non-formal sector. The strength of the network is oriented to all components that have interest to football.

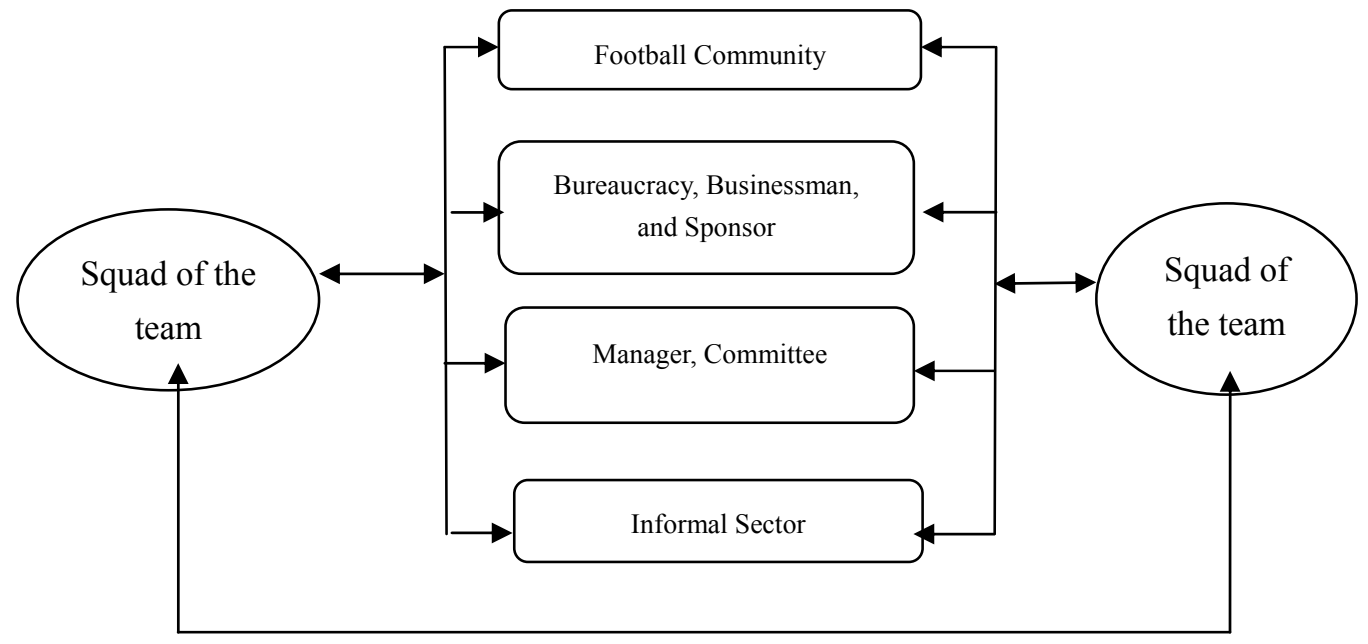

Figure 7. Network system in football 
Football playing techniques is teamwork. Each player with difference role has to maintain the consistency of his position. Thus, the selfishness is defeated by the desire to keep the playing cohesiveness.

The strong network in football proves that football accommodates all the differences presented on their players. Players' background (i.e. religious, cultural, and social background), in this case, is not quite important. It also proves that football is anti-racism game.

\subsubsection{Norms and Values}

Football is an activity that has been patterned, in which it shows social relation through cooperation, accommodation, acculturation, and competitiveness. In fact, a conflict often occur, such as between the players, the players and referee, and spectators of the squad. To handle this conflict, playing norms are required. Playing norms are a consensus that is set as the foundation of the football rules. Football players are attached to the norms and have to obey it. Football norms cover several aspects, which will be elaborated below:

- Norms that regulate players' custom

- Norms that regulate players' internal behaviors

- Norms that regulate the relationship with other teams

- Norms that regulate coaches and team officers

- Norms that regulate referees/ referee assistants

- Norms that regulate spectator behaviors

Those six norms are presented in football. They are required to keep the activity on the team.

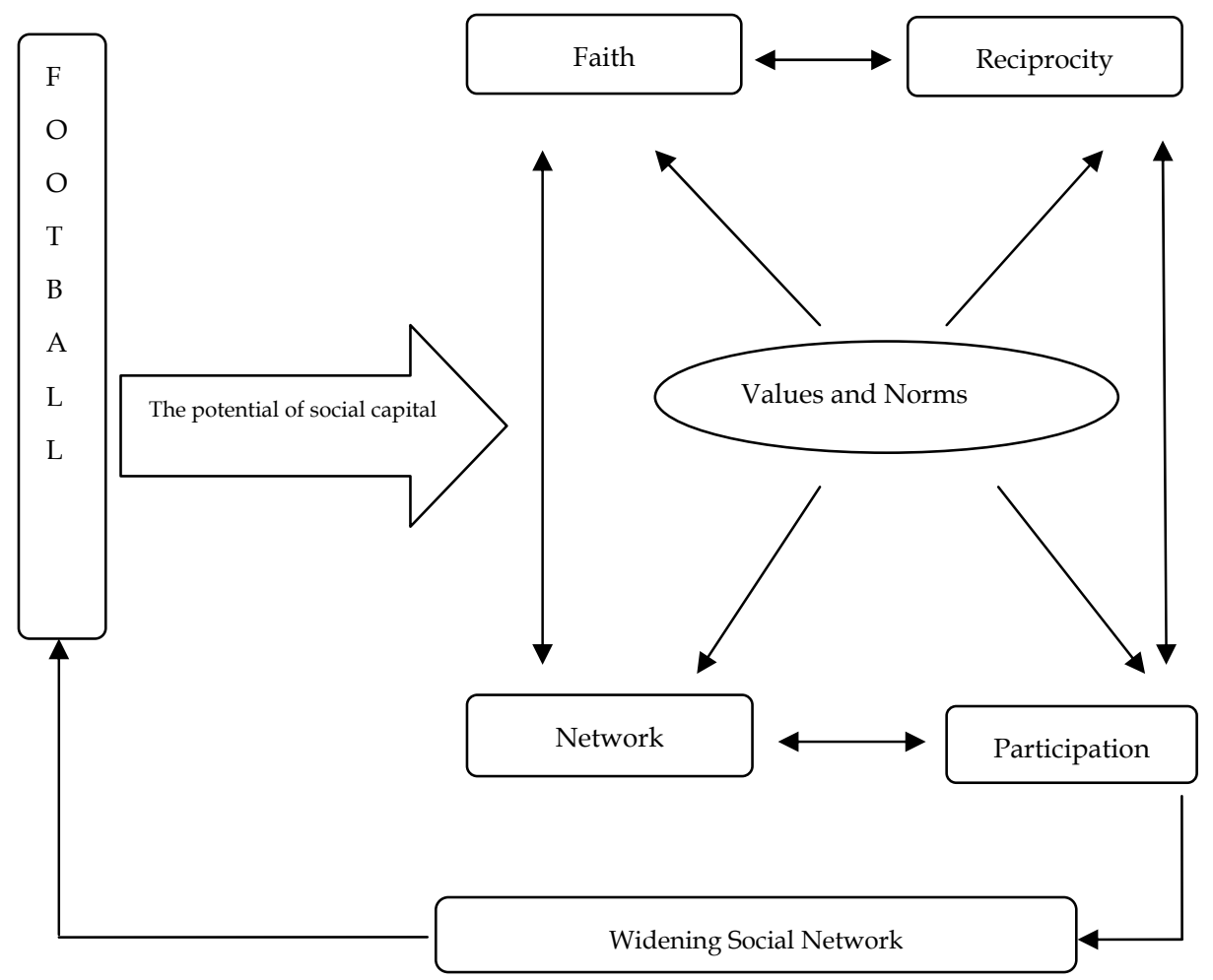

Figure 8 . The potency of social capital in football

According to Veegar (1986) human action is determined not only by the faith and motivation, but also by regulations, norms, and structures made collectively. In this case, one becomes a society because there is behavior pattern that regulates (folkways) such as habits, unwritten customs, moral norms that become law in the written form.

The four categories of behavior pattern (folkways) mentioned above are not social instinct or evolution laws which unity individuals, but they are cultural facilities that come from society initiative and collective behavior. By using those behavior patterns in social interaction, society attempts to solve practical difficulties. The process 
of social interaction, however, requires adaptation to the existing behavior patterns. If one can adapt these behaviors, it is assumed that he is suitable with the condition of the time and place. On the other hand, if one is not able to adjust the social interaction process with behavior patterns, it cause conflict. Therefore, it can be understood that in football, social interaction is patterned in strong network systems. This network is based on the norms agreed upon, which are used as a reference in managing the football. Regarding the social capital in PSM, following table (Table 6) will give a detailed description.

Table 6. Social capital in PSM

\begin{tabular}{|c|c|c|}
\hline No. & The Elements of Social Capital & Indicators \\
\hline \multirow[t]{8}{*}{1.} & Faith & a. Doing the role \\
\hline & & b. Being able to receive the other team 's win/ honest \\
\hline & & c. Admitting mistakes \\
\hline & & d. Understanding friends' skills \\
\hline & & e. Giving the same treatment to others \\
\hline & & f. Respecting Referee's decision \\
\hline & & g. Being able to control ourselves \\
\hline & & h. Descipline in esxecuting tasks \\
\hline \multirow[t]{8}{*}{2.} & Reciprocity & a. $\quad$ Supporting each other \\
\hline & & b. Understanding the signals given \\
\hline & & c. Having the same direction. \\
\hline & & d. Receiving and giving the ball \\
\hline & & e. Giving the advice \\
\hline & & f. Separating fighters \\
\hline & & g. Being able to receive the warning \\
\hline & & h. Being able to receive the background differences \\
\hline \multirow[t]{7}{*}{3.} & Participation & a. Keeping team cohesiveness \\
\hline & & b. Conducting coach's instruction. \\
\hline & & c. Playing according to determined game pattern \\
\hline & & d. Conducting Referee's decision \\
\hline & & e. Respecting the opposing team \\
\hline & & f. Keeping the game orderliness \\
\hline & & g. Being able to control emotion \\
\hline \multirow[t]{6}{*}{4.} & Social Network & $\begin{array}{ll}\text { a. } & \text { Relationship between players. }\end{array}$ \\
\hline & & b. Relationship with other teams \\
\hline & & c. Relationship with coach \\
\hline & & d. Relationship with the referee \\
\hline & & e. Relationship with spectators \\
\hline & & f. Relationship with the other football community members \\
\hline \multirow[t]{9}{*}{5.} & Values/Norms & a. $\quad$ Playing fair \\
\hline & & b. Having professional attitudes \\
\hline & & c. Helping each other \\
\hline & & d. Obeying the coach's instruction \\
\hline & & e. Knowing the position \\
\hline & & f. Noticing referee's instruction \\
\hline & & g. Avoiding racial discrimination \\
\hline & & h. Having individual awareness \\
\hline & & i. Having collective awareness \\
\hline
\end{tabular}


Social capital in PSM lately has been weakened. This is caused by inconsistency in recruiting foreign players and coaches. Besides, PSM management ignores the socio-cultural background of PSM itself. Another reason is a change in management orientation. The management orientation has been shift from local cultural to economics and commercial interest. In fact, from socio-cultural perspective, society still keeps collective behavior, trust, and strong reciprocity.

With continous changes society cannot contribute well to the football anymore. Meanwhile, nationally, Makassar Football Association (PSM) is one of the squad whose achievement has been stable. However, it has continued to perform avaragely in the Indonesian Super League (LSI). This achievement actually shows that PSM cannot play maximally at the national level. PSM's performance is lagged behind other better performing squads.

From the social capital context, the challenge faced is the development of social capital. Social capital development, in this case, does not consider local cultural facilities which have developed into normative values. This means that local cultural norms and cohesion values should be combined, developed, and assimilated with other external factors, such as modern management which is based on professionalism to develop sports in the region. The purpose of developing strong social capital is to create strong cohesive and networks based on faith, values, reciprocity, and participants.

In sports, the development of social capital should consider the local potential. This includes local cultural facilities which contain norms as basis to form players' character. One of the informants stated that $90 \%$ of PSM player are local people. This is a good condition since they will give support to the team based on local cultural bond and the club's character.

Historically, PSM cannot be separated from Bugis culture. It is a fact that local culture has some important values that can be used to develop the sport achievement, especially football. Bugis community has several main values, such as honesty, scholarly, decency, firm, and being zelious. PSM can strengthen its social capital if it can combine those local cultural values to develop the required network in football.

\section{Conclusion and Implications}

Football's contribution to the strengthening of social capital basically is a psychological aspect. It relies on attitude, behavior and it develops internally. In this case, it requires cooperation, accommodation, and healthy competition behaviors. Cooperation is about a strong relationship between individuals. In football, cooperation occurs before the match begins and focuses on individual contact. The aim is to create close relationships between the players. Cooperation happens during the match and its purpose is to strengthen internal solidarity and cohesion of the players. The cooperation at this stage depends on the playing formation and strategy determined by the coach. Cooperation, in this case, relies on individual activities in a group or team.

Regarding football contribution to the players- this refers to the physical, physiological, and social development of the individual players. Besides, the player will also have discipline, openness in their relationships with others, and will promote fair play, if well facilitated. In football, the development of players' characteristics has two processes. The first process is internalization of social and cultural values presented in football. The second process is adaptation model or socialization, in which the players do the interaction with the other players from different social and cultural background or with those who have different characteristics.

Social capital can build strong social networks based on faith, reciprocity, participation, and normative behaviors. These four aspects can be gained in football. Regarding faith, football players perform their roles according to their position in the team as it has been determined in the playing formation. They also have fair play attitude, discipline, and great efforts they believe the team is theirs. In term of reciprocity, football players attempt to put their individual interest and selfishness aside. The purpose is to create independent relationships between the players. In participation, the football players perform both their individual roles and collective tasks as a team, such as creating effective strategy to attack, controling the ball, and dominate the match. In social network, football is categorized as an activity that has a strong collective network, either in internal (players and managers) or external (economical organization, and bureaucratic) systems. Meanwhile, concerning values and norms, football really emphasizes the importance of obeying the playing rules and regulations. The players have to compete professionally based on the playing norms, in which its implementation is controlled by referees and referee assistants.

\section{Acknowledgments}

I thank the administration of Universitas Neggeri Makasssar for its financial support toward the study that led to this publication. 


\section{References}

Blumer, H. (1971, Winter). Social Problems as Collective Behavior. Social Problems, 18(3), 298-306. http://dx.doi.org/10.2307/799797

Burt, R. S. (1987). Social contagion and innovation, cohesion versus structural equivalence. American Journal of Sociology, 92, 1287-1335. http://dx.doi.org/10.1086/228667

Cohen, A. K. (1955). Delinquent Boys, The Culture of The Gang. New York.

Firth, R. (1966). Malay Fishermen: Their Peasant Economy. New York: W.W. Norton.

Hall, P. (1999). Social Capital in Britain. British Journal of Politics, 29, 417-461. http://dx.doi.org/10.1017/S0007123499000204

Hamid, A. (1998). Metodologi Penelitian Sosial, Suatu Stretegi, Teknik dan Taktik Wawancara. Jilid I dan II, PPS Universitas Hasanuddin.

Hasbullah, J. (2006). Social Capital: Menuju Keunggulan Budaya Manusia Indonesia. Jakarta: MR-United Press, Cetakan Pertama.

Johnson, D. P. (1986). Teori sosiologi klasik dan modern, jilid II / oleh Doyle Paul Johnson; diindonesiakan oleh Robert M.Z. Lawang, Jakarta: Gramedia.

Lickona, T. (1992). Educating for Character: How Our Schools Can Teach Respect and Responsibility. New York: Simon \& Schuster, Inc.

Mead, G. H. (1934). Mind, Self and Society. Chicago: University of Chicago Press.

Miles, M. B., \& Huberman, A. M. (1984). Qualitative Data Analysis. Baverly Hills, California: Sage Publication.

Narwako, J. D., \& Suyanto, B. (2010). Sosiologi Teks Pengantar Dan Terapan. Jakarta : Kencana Prenadamedia Group.

Natakusumah, A. (2008). Drama itu Bernama Sepak Bola Gambaran Silang Sengkarut Olah Raga. Politik dan Budaya, Jakarta: Elex Media Komputindo, Cetakan Pertama.

Ni'am, H. (2008). Euro 2008 dan Modal Sosial. Website.

Nopembri, S. (2008). Model Pengembangan Keterampilan Sosial Melalui Olahraga Futsal (Studi Interaksi Sosial pada Masyarakat yang Berpartisipasi dalam Olahraga Futsal). Desertasi; UNHAS.

Parkinson, B. (1967). Non-Economic Factors in the Economic Retardation of the Malays. Modern Asian Studies, 101, 36-38.

Putnam, D. R. (1993). Making Democracy Work: Civic Traditions in Modern Italy. Princeton: Prince- ton University Press.

Ritzer, G., \& Goodman, D. J. (2003). Sociological Theory (6th ed.). London: McGraw-Hill.

Rivai. (2007). Modal Sosial Masyarakat Bugis di Perkampungan Nelayan Anetue-Kaca Kabupaten Soppeng, Desertasi, UNHAS.

Simmel, G. (1990). The Philosophy of Money (2nd ed.). Routledge, London.

Sugiyono. (2005). Memahami Penelitian Kualitatif. Bandung: Alfabeta.

Sumanto, Y. et al. (1993). Strategi Belajar dan Mengajar. Jakarta : Depdikbud.

Sunarto, K. (1993). Pengantar Sosiologi. Jakarta: Lembaga Penerbit Fakultas Ekonomi Universitas Indonesia.

Veeger, K.J. (1986). Realitas Sosial. Jakarta: PT Gramedia.

Wellman, B. (1983). Network Analysis: Some Basic Principles. Sociological Theory, 1, 155-200. http://dx.doi.org/10.2307/202050

\section{Copyrights}

Copyright for this article is retained by the author(s), with first publication rights granted to the journal.

This is an open-access article distributed under the terms and conditions of the Creative Commons Attribution license (http://creativecommons.org/licenses/by/3.0/). 